\title{
Correlations between Depth of Water Penetration, Chloride Permeability, and Coefficient of Chloride Diffusion in Plain, Silica Fume, and Fly Ash Cement Concretes
}

\begin{abstract}
An experimental study was conducted to evaluate correlations between the depth of water penetration, chloride permeability, and coefficient of chloride diffusion in plain, silica fume, and fly ash cement concretes. A total of 27 concrete mixtures were prepared by varying the water to cementitious materials ratio and cementitious materials content and using Type I, fly ash (20\%), and silica fume (7.5\%) cements. The test results were statistically analyzed to develop correlations between the depth of water penetration, chloride permeability, and coefficient of chloride diffusion. A good correlation was noted between the depth of water penetration and chloride diffusion, and Chloride permeability and coefficient of chloride diffusion $\left(R^{2}>0.80\right)$.
\end{abstract}

KEYWORDS: plain and blended cement concretes, durability characteristics, statistical analysis, correlation between properties

\section{Introduction}

Movement of pure water or diffusion of aggressive ions. such as chlorides and sulfates, influences the durability of concrete. Movement of fluids through concrete takes place in different ways, such as flow under a pressure differential, termed as "permeability," capillary movement in the pores, termed as "sorption," and due to differences in concentration, termed as "diffusion." In addition to the exposure conditions. the aforesaid transport phenomena primarily depend on the concrete's microstructure [I]. The microstructure of concrete is influenced by a number of factors that include: water/cementitious materials ratio, type, and the quantity of the cementitious materials, aggregate size and proportion, admixtures used, and methods of preparation, placement, and curing [2].

Durability of concrete is generally assessed by measuring the depth of water penetration according to DIN 1048 [3], evaluating chloride permeability according to ASTM C 1202 [4], and determining the coefficient of chloride diffusion using Fick's second law, as described by Crank [5]. The determination of depth of water penetration and chloride permeability provides a qualitative indication of the durability of concrete. Further, these values are often not useful [or predicting the time to initiation and rate of reinforcement corrosion. On the other hand, the chloride diffusion coefficient is very useful in predicting the time to initiation of reinforcement corrosion in concrete exposed to chloride environments [6]. However, the determination of chloride diffusion coefficient is difficult and requires a very long exposure time, as compared to the measurement of depth of water penetration and chloride permeability. Since the aforesaid three paran1eters primarily depend on the microstructure of concrete, there is a possibility of correlating them with each other, so that a particular paran1eter that is difficult to measure (e.g., chloride diffusion coefficient) could be determined by measuring

Manuscript received February 20. 2007; accepted for publication September 27, 2007; published online November 2007.

${ }^{1}$ King Fahd University of Petroleum and Minerals. Dhahran 31261, Saudi Arahia. another parameter, such as chloride permeability or depth of water penetration.

Several research studies have been reported in the literature on the correlation between the durability parameters. Armaghani et al. [7] established a correlation between the results of the Florida water permeability test and those of AASHTO T-277 [8] chloride permeability test which is similar to ASTM C 1202 [4]. A unique relationship between the Coulomb and migration coefficient of chloride ions fof plain and blended cement concretes was reported by Sugiyama et al. [Q]. Yang [10], in his study on the relationship between the pore structure and chloride diffusivity in cement-based materials, obtained a linear relationship between the steady-state migration coefficient and nonsteady-state migration coefficient based on the same experimental setup and specimens. A relationship between the effective diffusion coefficient and the depth of chloride penetration under the action of an electric field was reported by Luping and Nilsson [11). Ramezanianpour et al. [12] developed a correlation between the chloride permeability and chloride diffusion coefficient using a neural network system. Yang and Cho [13] and Yang [14] have found a linear correlation between the chloride diffusion coefficient and charge passed (i.e., chloride permeability). A correlation between the chloride diffusion coefficient and gas permeability of concrete was reported by Sugiyama et al. [15]. Equations relating the effective chloride diffusion coefficient with resistivity and permeability of concrete have been developed by Berke and Hicks [16].

There is an increasing trend to specify concrete in terms of both strength and durability in order to enhance the useful service-life of structures. Among the durability indices, coefficient of chloride diffusion is more relevant. However, its determination is difficult and time consuming. On the other hand, the depth of water penetration and chloride permeability could be determined with much more ease and at less expense and time. Therefore, there is a need to develop correlaticll1s between the depth of water penetration, chloride permeability, and coefficient of chloride diffusion. Such correlations would provide an empirical guidance en determining the 
coefficient of chloride diffusion if chloride permeability or the depth of water penetration is known. In the present study, the depth of water penetration, chloride permeability, and coefficient of chloride diffusion were measured on 27 plain, silica fume, and fly ash cement concrete mixtures by varying the mixture proportions (i.e., water to binder ratio and cementitious materials content). The test results were analyzed to develop correlations between the depth of water penetration, chloride permeability, and coefficient of chloride diffusion.

\section{Experimental Program}

Type I cement, silica fume and fly ash were used to prepare plain and blended cement concrete mixtures. Silica fume $(7.5 \%)$ and fly ash $(20 \%)$ were used to replace Type I cement by mass. Crushed limestone was used as the coarse aggregate while dune sand was used as the fine aggregate. The coarse aggregate grading conformed to ASTM C 33 [17] (\#7) limits. The specific gravity and water absorption of the coarse aggregate were 2.55 and $2.5 \%$, respectively. For fine aggregates, these values were 2.65 and $0.5 \%$, respectively.

In order to develop test data over a wide and practical range, the following mix design parameters were utilized in the preparation of the concrete mixtures:

Cementitious materials content:

$$
\begin{gathered}
300,350 \text {, and } 400 \\
\mathrm{~kg} / \mathrm{m}^{3}
\end{gathered}
$$

Water/cementitious materials ratio: $\quad 0.35,0.40,0.45$, and 0.50 (by mass)

Coarse / total aggregate ratio:

0.68 (by mass, constant in all mixtures)

All the concrete mixtures were designed for a workability of 75 to $100 \mathrm{~mm}$ slump. Suitable dosage of a high-range water reducer was added to the concrete to obtain the desired workability.

The depth of water penetration was measured according to DIN 1048 [3] while the chloride permeability was determined according to ASTM C 1202 [4].

For determining the coefficient of chloride diffusion, three $75-\mathrm{mm}$ diameter and $150-\mathrm{mm}$ high concrete cylinders were first cured for 28 days. Thereafter, they were allowed to dry in the laboratory for seven days and then they were coated with an epoxy resin on the curved surface and one of the flat surfaces to allow uniaxial diffusion of chloride ions. The specimens were dried to ensure a good bond between the concrete substrate and the epoxy coating. The coated specimens were immersed in a $5 \%$ sodium chloride solution for six months. After this period, they were cleaned and dried to remove the surface moisture and thin slices of concrete were thereafter obtained at $5,15,35,50$, and $75 \mathrm{~mm}$ by dry cutting. The slices were pulverized and ground to a fine powder passing through \#100 sieve. In order to determine the concentration of water-soluble chlorides, three grams of the powder were dissolved in $50 \mathrm{~mL}$ of hot distilled water. The solution was kept in a mechanical shaker for 24 hours and, thereafter, it was filtered and the filtrate was diluted to $100 \mathrm{~mL}$. The filtrate was analyzed for water-soluble chloride content in accordance with AASHTO T-260 [18]. The chloride concentration was plotted against the concrete depth to ascertain the chloride concentration profile that was utilized to determine the coefficient of chloride diffusion according to Fick's second law of diffusion, as described by Crank [5].
TABLE 1-Depth of water penetration, chloride permeability, and coefficient of chloride diffusion in plain cement concrete specimens.

\begin{tabular}{lcccc}
\hline $\begin{array}{l}\text { Cementitious } \\
\text { Materials } \\
\text { Content } \\
\left(\mathrm{kg} / \mathrm{m}^{3}\right)\end{array}$ & $\begin{array}{c}\text { Depth of } \\
\text { Water } \\
\text { W/cm } \\
\text { Ratio }\end{array}$ & $\begin{array}{c}\text { Rapid } \\
\text { Penetration } \\
\text { Chloride }\end{array}$ & $\begin{array}{c}\text { Chloride } \\
\text { Permeability } \\
(\text { Coulombs })\end{array}$ & $\begin{array}{c}\text { Diffusion } \\
\text { Coefficient } \\
\left(\times 10^{8} \mathrm{~cm}^{2} / \mathrm{s}\right)\end{array}$ \\
400 & 0.35 & 41 & 2875 & 6.12 \\
350 & 0.35 & 36 & 2445 & 7.31 \\
400 & 0.411 & 47 & 3639 & 8.12 \\
300 & 0.46 & 44 & 3271 & 8.02 \\
350 & 0.45 & 56 & 3984 & 15.00 \\
400 & 0.45 & 50 & 3820 & 13.10 \\
350 & 0.45 & 48 & 3593 & 12.50 \\
400 & 0.50 & 89 & 5614 & 22.00 \\
\hline
\end{tabular}

\section{Results and Discussion}

The depth of water penetration, chloride permeability, and coefficient of chloride diffusion, determined for plain, silica fume, and fly ash cement concrete specimens are presented in Tables 1-3. The effect of the two variables, water to cementitious materials $(\mathrm{w} / \mathrm{cm})$ ratio and cementitious materials content, can be seen through the observation of the test results for all the three types of concretes. It can be noted that an increase in the w/ $\mathrm{cm}$ ratio decreases the durability of both plain and blended cement concretes while an increase in the cementitious materials content enhances it. The effect of ce-

TABLE 2-Depth of weter nenetration, chloride permeabilits; and coefficient of hloride diffusion in silica fume cement concrete specimens.

\begin{tabular}{lcccc}
\hline $\begin{array}{l}\text { Cementitious } \\
\text { Materials } \\
\text { Content } \\
\left(\mathrm{kg} / \mathrm{m}^{3}\right)\end{array}$ & $\begin{array}{c}\text { Depth of } \\
\text { Water } \\
\text { W/em }\end{array}$ & $\begin{array}{c}\text { Penetration } \\
\text { Ratio }\end{array}$ & $\begin{array}{c}\text { Chloride } \\
\text { Permeability } \\
(\text { Coulombs })\end{array}$ & $\begin{array}{c}\text { Chloride } \\
\text { Diffusion } \\
\text { Coefficient } \\
\left(\times 10^{-3} \mathrm{~cm}^{2} / \mathrm{s}\right)\end{array}$ \\
\hline 350 & 0.35 & 23 & 820 & 1.22 \\
400 & 0.35 & 21 & 782 & 1.08 \\
350 & 0.40 & 35 & 995 & 1.64 \\
400 & 0.40 & 31 & 866 & 1.54 \\
300 & 0.45 & 49 & 1242 & 2.11 \\
350 & 0.45 & 41 & 1329 & 1.81 \\
400 & 0.45 & 35 & 1149 & 1.37 \\
350 & 0.50 & 50 & 2591 & 2.33 \\
400 & 0.50 & 4.4 & 2019 & 1.88 \\
\hline
\end{tabular}

TABLE 3-Depth of water penetration, chloride permeability; and coefficien of chloride diffusion in fly ash cement concrete specimens.

\begin{tabular}{lcccc}
\hline $\begin{array}{l}\text { Cementitious } \\
\text { Materials } \\
\text { Content } \\
\left(\mathrm{kg} / \mathrm{m}^{3}\right)\end{array}$ & $\begin{array}{c}\text { Depth of } \\
\text { Water } \\
\text { Wenetration } \\
(\mathrm{mm})\end{array}$ & $\begin{array}{c}\text { Chloride } \\
\text { Permeability } \\
\text { (Coulombs) }\end{array}$ & $\begin{array}{c}\text { Chloride } \\
\text { Diffusion } \\
\text { Coefficient } \\
\left(\times 10^{-8} \mathrm{~cm}^{2} / \mathrm{s}\right)\end{array}$ \\
\hline 350 & 0.35 & 32 & 1603 & 2.12 \\
400 & 0.35 & 31 & 1477 & 1.66 \\
350 & 0.40 & 44 & 1769 & 2.41 \\
400 & 0.40 & 38 & 1630 & 2.02 \\
300 & 0.45 & 48 & 2219 & 4.23 \\
350 & 0.45 & 46 & 2510 & 4.16 \\
400 & 0.45 & 45 & 2220 & 3.05 \\
350 & 0.50 & 57 & 3548 & 5.32 \\
400 & 0.50 & 51 & 2750 & 4.85 \\
\hline
\end{tabular}




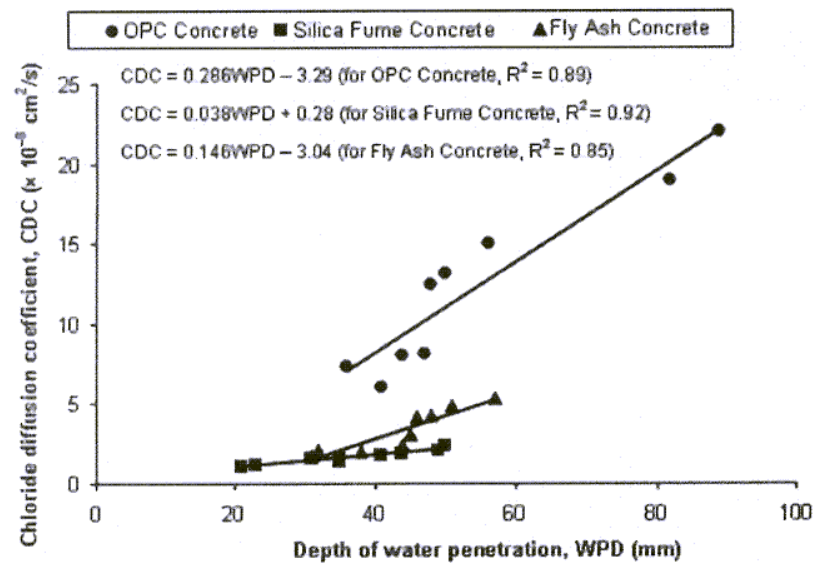

FIG. 1-Relationship between depth of water penetrution and coefficient of chloride diffusion.

mentitious materials content is marginal at lower w/cm ratio $(0.35$ and 0.40$)$ and significant at higher w/em ratios $(0.45$ and 0.50$)$, particularly at 0.50 . The effect of adding silica fume and fly ash on the durability characteristics is also observed. For a given $w / \mathrm{cm}$ ratio and cementitious materials content, plain cement concrete is the least durable while silica fume cement concrete is the most durable.

To develop correlation equations between the investigated durability characteristics, the depth of water penetration is plotted against the coefficient of chloride diffusion in Fig. 1, while the depth of water penetration is plotted against the chloride permeability in Fig. 2. The coefficient of chloride diffusion is correlated with chloride permeability in Fig. 3. As shown in Figs. 1 and 2, both chloride diffusion coefficient and chloride permeability increase with an increase in the depth of water penetration. However, for a certain depth of water penetration, the chloride diffusion and chloride permeability are different for the three types of concretes. Both the chloride permeability and chloride diffusion values are the least in the silica fume cement concrete, followed by fly ash and plain cement concretes in the increasing order. Thus, the positive effect of supplementary cementing materials in decreasing chloride ingress is evident. $A$ similar trend could be observed between the

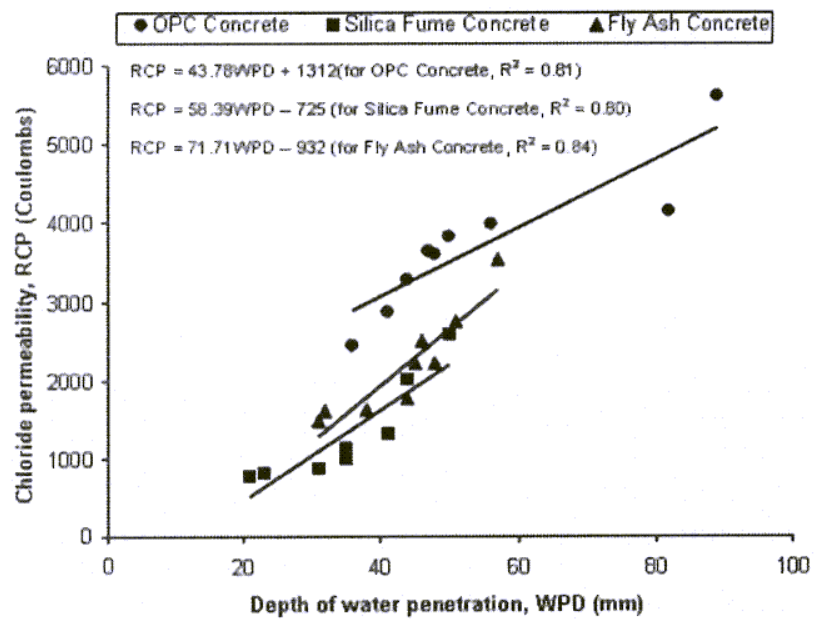

FIG. 2 Relationship between depth of water penetration and chloride permeability.

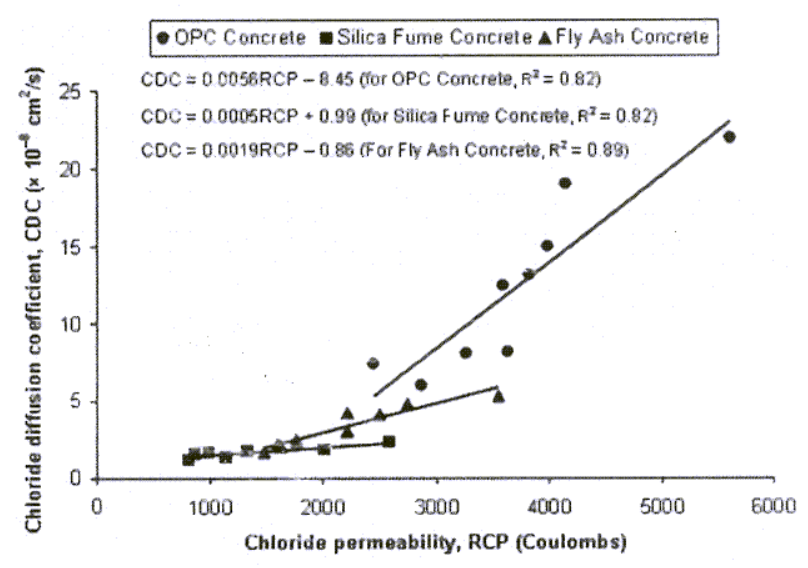

FIG. 3 Relationship between chloride permeability and coefficient of chloride diffusion

chloride permeability and coefficient of chloride diffusion, as shown in Fig. 3. The coefficient of chloride diffusion increased linearly with the chloride permeability of concrete

The best-fit equations and the coefficients of correlation $\left(R^{2}\right)$, obtained by statistical anaiysis of the experimental data, are summarized in Table 4. The correlation coefficients are generally more than 0.80 , indicating a good correlation beiween the three durability indices [19]. While all the points were considered in the statistical analysis, one of the nine points, that indicated a significant variation between the experimental and fitted value $(>50 \%)$ in the correlation betwecin chicride permeability and depth of water penetration for silica fume concrete, was not considered in the statistical analyses. Similarly, two of the nine data points, that showed a variation of more than $25 \%$, were not considered in the statistical analysis to get a better correlation between chloride diffusion coefficient and chloride permeability.

The best-nit models relating the coefficient of chloride diffusion with the depth of water penetration and chloride permeability for plain, silica fume, and fly ash cement concretes may be useful for a quick determination of the coefficient of chloride diffusion by substituting either of these values in the respective models. However, it should be noted that the properties of concrete are dependent not only on the mix design parameters, but on the cement type. Also, it

TABLE 4-Correlation cquations betwen the durability indices.

\begin{tabular}{|c|c|c|c|}
\hline Correlation between & Concrite & Correlation Equation & $R^{2}$ \\
\hline \multirow{3}{*}{$\begin{array}{l}\text { Chloride diffusion } \\
\text { coefficient and depth of } \\
\text { water penetration }\end{array}$} & ON & $C D C=0.286 \mathrm{WPI} \quad 3.29$ & 0.89 \\
\hline & Silica fume & $C D C=0.038 W P D+0.28$ & 0.92 \\
\hline & Fly ash & $C D C=0.146 \mathrm{WPD}-3.04$ & 0.85 \\
\hline \multirow{3}{*}{$\begin{array}{l}\text { Chloride permeability and } \\
\text { depth of water penetration }\end{array}$} & $\mathrm{OPC}$ & $\mathrm{RCP}=43.783 \mathrm{WPD}+1312$ & 0.81 \\
\hline & siiica fume & $\mathrm{RCP}=58.393 \mathrm{WPD}-725$ & $0.80^{4}$ \\
\hline & Fly a: & $\mathrm{RCP}=71.714 \mathrm{WPD}-932$ & 0.84 \\
\hline \multirow{3}{*}{$\begin{array}{l}\text { Chloride permeability and } \\
\text { chloride diffusion } \\
\text { coefficient }\end{array}$} & $\mathrm{OPC}$ & $\mathrm{CDC}=0.0056 \mathrm{RCP}-8.45$ & 0.82 \\
\hline & Silica fume & $C D C=0.0005 R C P+0.99$ & $0.82^{\mathrm{b}}$ \\
\hline & Fly ash & $C D C=0.0019 R C P \quad 0.86$ & 0.89 \\
\hline
\end{tabular}

Notes: WPD-defiti of water penetration $(\mathrm{mm})$. RCP $=$ Chloride permeability (Coulombs). $\mathrm{CDC}=$ Chloride diffusion coefficient $\left(\times 10^{-8} \mathrm{~cm}^{2} / \mathrm{s}\right)$.

"One of the nine data points exhibiting high coefficient of variation was deleted to obtain a good fit.

'Two of the nine data points exhibiting high coefficient of variation were deleted to obtain a good fit. 
may not be rational to relate the absorption characteristics with the diffusion properties. Therefore, the correlations developed in this study, particularly those relating the depth of water penetration to the coefficient of chloride diffusion should be used with caution. They can, however, at best be utilized to calculate approximate values.

\section{Conclusions}

Based on the data developed in this investigation, the following conclusions could be drawn:

- The coefficient of chloride diffusion, chloride permeability, and depth of water penetration decreased with decreasing water to cementitious materials ratio and increasing cement content. However, these properties varied with the type of cement, being the least in the silica fume cement concrete followed by fly ash and plain cement concretes in increasing order.

- Good correlation was noted between the coefficient of chloride diffusion and the depth of water penetration and coefficient of chloride diffusion and chloride permeability. The correlation coefficients $\left(R^{2}\right)$ were more than 0.80 .

- The correlations developed in the present study could be utilized to determine the coefficient of chloride diffusion utilizing the depth of water penetration or chloride permeability. However, it should be noted that the values obtained from the correlation equations are valid for the cement types and mix design parameters investigated in the reported study. Therefore, the results obtained utilizing the correlation equations for other mixes would at best provide an approximate indication of the desired properties of concrete.

\section{Acknowledgments}

The authors acknowledge the support received for this research under grant ARI-022 from the Research Institute and the Civil Engineering Department at King Fahd University of Petroleum and Minerals, Dhahran, Saudi Arabia.

\section{References}

[1] Neville. A. M., Properties of Concrete, 4th ed., Prentice Hall, London, 2002

[2] Al-Amoudi, O. S. B., Maslehuddin, M., and Rasheeduzzafar, "Permeability of Concrete: Influential Factors," 4th Internalional Conference on Deterioration and Repair of Reinforced Concrete in the Arabian Gulf, Bahrain, 1993, pp. 717-733.

[3] DIN 1048, "Testing of Hardened Concrete," Deutsches Institut Fur Normung, Germany, 1991.

[4] ASTM Standard C 1202, "Electrical Indication of Concrete's
Ability to Resist Chloride Ion Penetration," Annual Book of ASTM Standards, ASTM International, West Conshohocken, PA, Vol. 4.02, 2005

[5] Crank, J., The Mathematics of Diffusion, 2nd ed., Oxford University Press, New York, 1999

[6] Azad, A. K., Sharif, A. M., Navaz, M., and Loughlin, K. F.. "Chloride Diffusion Coefficient of Concrete in the Arabian Gulf Environment," Arabian J. Sci. Eng., Vol. 22, No. 2B, 1997, pp. 169-182.

[7] Armaghani, J. M., Larsen, T. J., and Romano, D. C., "Aspects of Concrete Strength and Durability," Transp. Res. Rec., No. 1335, 1992, nn. 63-69.

[8] AASHTO T-277 "Standard Method for Electrical Indication of Concrete's Ability to Resist Chloride Ion Penetration." American Association of State Highway and Transportation Officials, Washington, DC, 2005.

[9] Sugiyama, T.. Tsuji, Y., and Bremner, T. W., "Relationship between Coulomb and Migration Coefficient of Chloride Ions for Concrete in a Steady-State Chloride Migration Test," Mag. Concrete Res., Vol. 53, No. 1, 2001, pp. 13-24.

[10] Yang, C. C., "On the Relationship between Pore Structure and Chloride Diffusivity from Accelerated Chloride Migration Test in Cement-Based Materials," Cem. Concr. Res., Vol. 36 , No. 7, 2006. pp. 1304-1311.

[11] Luping, T. and Nilsson, L. O., "Rapid Determination of the Chloride Diffusivity in Concrete by Applying an Electric Field," ACl Mater. J., Vol. 89, No. 1, 1992, pp. 40-53.

[12] Ramezanianpour, A. A., Ashraf, H. R., and Khademi, M. "Diffusion Coefficient of Chloride lons under Simulated Conditions," International Conference on Cement Combinations for Durable Concrete, Dundee, Scotland, UK, 2005, pp. 639 650.

[13] Yang, C. C. and Chao, S. W., "An Electrochemical Method for Accelerated Chloride Migration Test of Diffusion Coefficient in Cement-Based Materials," Mater: Chem. Phys, Vol. 81, No. 1, 2003, pp. $116-125$.

[14] Yang, C. C., "Relationship between Migration Coefficient of Chloride Ions and Charge Passed in Steady State," ACI Mater. J. Vol. 101, No. 2, 2004, pp. 124-130.

[15] Sugiyama, T., Bremner, T. W., and Tsuji, Y., "Determination of Chloride Diffusion Coefficient and Gas Permeability of Concrete and Their Relationship," Cem. Concr. Res., Vol. 26, No. 5, 1996, pn. 781-790.

[16] Berke, N. S. and Hicks, M. C., "Predicting Chloride Profiles in Concrete," Corrosion (Houston), Vol. 50, No. 3, 1994. pp. 234-239.

[17] ASTM Standard C 33, "Standard Specifications for Concrete Aggregates," Annuai Book of ASTM Standards, ASTM International, West Conshohocken, PA, Vol. 4.02, 2005.

[18] AASHTO 1-260, "Standard Method of Test for Sampling and Testing for Chloride isil in Concrete and Concrete Raw Materials," American Association of State Highway and Transportation Officials, Washington, DC, 1997.

[19] Montgomery, D. C. and Peck, E. A., Introduction to Linear Regression Analysis, Wiley, New York, 1982. 